\title{
Commentary: Systems Biology Approach to Model the Life Cycle of Trypanosoma cruzi
}

\author{
Alejandra Carrea ${ }^{1,2 *}$ and Luis Diambra ${ }^{1,2}$ \\ ${ }^{1}$ Laboratorio de Biología de Sistemas, Centro Regional de Estudios Genómicos, Facultad de Ciencias Exactas, Universidad \\ Nacional de La Plata, La Plata, Argentina, ${ }^{2}$ Consejo Nacional de Investigaciones Científicas y Técnicas, Argentina
}

Keywords: gene regulatory network, Trypanosoma cruzi, metabolic enzymes, moonlighting proteins, computational approaches

\section{A commentary on}

Systems Biology Approach to Model the Life Cycle of Trypanosoma cruzi

by Carrea, A., and Diambra, L. (2016). PLoS ONE 11:e0146947. doi: 10.1371/journal.pone.0146947

In a recent work we have identified, from a bigger gene regulatory network, a seven-node module involved in the control of the life cycle of Trypanosoma cruzi (T. cruzi) (Carrea and Diambra, 2016). To that end, we have analyzed microarray gene-expression data of the four different T. cruzi's life cycle stages, by means of a systems biology approach. The found module is the smallest gene regulatory subnetwork able to emulate the dynamical properties of the parasite.

OPEN ACCESS

Edited by:

Claudio Silva,

Federal University of Uberlandia, Brazil

Reviewed by:

Luciana Oliveira Andrade,

Universidade Federal de Minas Gerais,

Brazil

Jie Zheng,

University of Pennsylvania, USA

Diana Bahia

Universidade Federal de Minas Gerais,

Brazil

${ }^{*}$ Correspondence:

Alejandra Carrea

carrea.alejandra@gmail.com

Received: 20 November 2016 Accepted: 03 January 2017

Published: 18 January 2017

Citation:

Carrea A and Diambra L (2017)

Commentary: Systems Biology

Approach to Model the Life Cycle of

Trypanosoma cruzi.

Front. Cell. Infect. Microbiol. 7:1.

doi: 10.3389/fcimb.2017.00001
This module is composed of nine genes: three of them coding for uncharacterized proteins, and the other six genes coding for characterized proteins. The latter code for: a hexokinase, a $\delta$-1pyrroline-5-carboxylate dehydrogenase, a quinone oxidoreductase, a glutamate dehydrogenase, a peptidyl-prolyl cis-trans isomerase, and a metaciclina II. Except for metaciclina II, these genes code for proteins involved in metabolic pathways. Thus, we were expecting gene-expression regulatory proteins instead of the striking information we obtained. Yet, it eventually became clear that these metabolic enzymes could have other regulatory functions beyond their known metabolic one. This type of multifunctional proteins are known as moonlighting proteins (Jeffery, 1999). They were first discovered in the late 1980s by Piatigorsky et al. (1988). They found that the lens structural protein $\delta$-crystallin and the metabolic enzyme argininosuccinate lyase are both encoded by the same gene in ducks. Today, it is well-known that moonlighting proteins comprise diverse kinds of proteins, and that they are present in many different organisms including animals, plants, yeasts, prokaryotes, and protists (for reviews see Jeffery, 2009; Huberts and van der Klei, 2010; Jeffery, 2014).

Moonlighting proteins characterized so far in unicellular parasites are mostly enzymes. Examples of these parasite's moonlighting enzymes include: a hexokinase in Leishmania donovani, which functions as a hemoglobin receptor within the parasite's flagellar pocket; the glycolytic enzyme aldolase in Toxoplasma gondii and Plasmodium falciparum, which has an additional (even if non-essential) function in host-cell invasion; various soluble metabolic enzymes in Trichomonas vaginalis, which moonlight as adhesins allowing parasite-host cell adhesion; the mitochondrial peroxiredoxin in Leishmania infantum, which not only functions as a peroxidase, but also as a chaperone essential for pathogenesis; the $\alpha$-ketoglutarate dehydrogenase E2 in bloodstream Trypanosoma brucei, which moonlights in the mitochondria ensuring a correct kinetoplast DNA inheritance (Collingridge et al., 2010; Ginger, 2014). Recently, Ferreira and colleagues have shown that the enzyme mevalonate kinase, originally involved in sterol isoprenoids biosynthesis in T. cruzi's glycosomes, is also secreted and may modulate host cell signaling during parasite invasion (Ferreira et al., 2016). 
A search carried out in two different moonlighting protein databases (MoonProt: http://www.moonlightingproteins.org Mani et al., 2015, and MultitaskProtDB: http://wallace.uab. es/multitask Hernández et al., 2014) showed that for the five metabolic enzymes that comprise the above mentioned module, there exist homologous enzymes in other organism/s with proven moonlighting function/s (Table 1). Another fact that came to light from this search is that, until now, there is no record of proteins moonlighting in T. cruzi in these two databases. Furthermore, there are several other examples in literature showing that some of these five enzymes actually moonlight, or have the potential to do so, in different organisms. We have previously mentioned hexokinase moonlighting as a hemoglobin receptor in Leishmania donovani (Collingridge et al., 2010). Mantilla and colleagues have proposed that T. cruzis $\delta$-1-pyrroline-5-carboxylate dehydrogenase has additional functions beyond the production of glutamate (Mantilla et al., 2015). They have suggested that this enzyme could be involved in the infection process, interacting with components of the mammalian host cells. They have based this hypothesis in enzyme structural data, in its mitochondrial membrane localization, and in its higher activity observed during the infective stages of the parasite. Another example is the peptidyl-prolyl cis-trans isomerase known as Mip, which moonlights as a host collagen IV biding protein in Legionella pneumophila. Rasch and colleagues have identified a 13-aminoacid-long peptide in collagen IV as the target of Mip, and have found that blocking this binding causes a decrease in bacterial transmigration in vitro (Rasch et al., 2014).

Taking all of the above into consideration, it follows that not limiting the functions of a given protein to its canonical one, while keeping in mind that it could be a moonlighting protein, is of the uppermost importance. Moreover, in the search of new therapeutic targets, it would be interesting and useful to investigate these moonlighting functions in previously well characterized proteins. In doing so, it must be remembered that moonlighting proteins constitute a major challenge when it comes to predicting their functions based solely on sequence homology or on conserved domains. This analysis could lead to the loss of some proteins' functions or to the assignment of wrong functions to other proteins (Jeffery, 2014, 2015). To overcome this difficulty, computational approaches combining several types of data (available omics-scale data, functional annotations in public databases, bioinformatics predictions, computational simulations of pathways, molecular dynamics of biomolecules, and other biochemical data) have been developed (Khan and Kihara, 2014; Khan et al., 2014). These integrative computational strategies will allow us to deepen our knowledge of moonlighting proteins and, therefore improve the design of drugs that must affect only the desired function of the target protein (Khan and Kihara, 2014), and will also help us understand how and why these proteins can be essential during infection, virulence or immune responses (Jeffery, 2014, 2015).

Finally, in relation to $T$. cruzi's pathogenesis, all these progresses could increase our current knowledge of hostparasite interactions, and help accelerate the discovery of effective drugs against Chagas disease. In a systems biology context, moonlighting proteins can function as a link or switch between two different pathways, and aid the cell to respond to environmental changes (Jeffery, 2014, 2015). Transitions between two different developmental stages in T. cruzi may be triggered by environmental changes such as the availability of nutrients or energy sources. To mention one representative

TABLE 1 | Moonlighting functions of the five enzymes that comprise the module controlling the T. cruzi's life cycle in other organisms, according to MoonProt and MultitaskProtDB.

\begin{tabular}{|c|c|c|c|}
\hline Enzyme Name & Uniprot ID of the Homologous Enzyme in T. cruzi & Moonlighting Function (Organism) & Reference \\
\hline \multirow[t]{6}{*}{ Hexokinase } & Q4D3P5 & Glucose signaling - Porine binding - & Moore et al., 2003 \\
\hline & & Apoptosis - Intracellular glucose & \\
\hline & & sensor (A. thaliana) & \\
\hline & & Apoptosis (E. coli) & Sukumaran et al., 2010 \\
\hline & & Transcriptional regulation & Moreno and Herrero, 2002 \\
\hline & & (S. cerevisiae) & \\
\hline$\delta$-1-pyrroline-5-carboxylate & Q4DRT8 & Transcriptional repression of the & De Spicer et al., 1991 \\
\hline \multirow[t]{3}{*}{ dehydrogenase } & & put operon (S. typhimurium) & De Spicer and Maloy, 1993 \\
\hline & & Transcriptional repression of the & Wood, 1981 \\
\hline & & put operon (E. coli) & \\
\hline \multirow[t]{2}{*}{ Quinone oxidoreductase } & Q4DHH8 & Lens crystallin (C. porcellus) & Rao et al., 1992 \\
\hline & & Lens crystallin (H. japonica) & Fujii et al., 2001 \\
\hline \multirow[t]{2}{*}{ Glutamate dehydrogenase } & Q4DWV8 & Transcription factor binding & Gunka et al., 2010 \\
\hline & & activity (B. subtilis) & \\
\hline \multirow{5}{*}{$\begin{array}{l}\text { Peptidyl-prolyl cis-trans } \\
\text { isomerase }\end{array}$} & Q4E4L9 & Induces apoptosis of gastric epithelial & Basak et al., 2005 \\
\hline & & cells - Activates monocyte IL-6 & \\
\hline & & synthesis $(H$. pylori) & \\
\hline & & Extracellular function: & Jin et al., 2004 \\
\hline & & proinflammatory cytokine (H. sapiens) & \\
\hline
\end{tabular}


example, it was demonstrated that L-proline amino acid plays an essential role during intracellular differentiation of T. cruzi in the mammalian host (Tonelli et al., 2004). This raises the possibility that enzymes participating in metabolic pathways could be, in addition, moonlighting proteins. Therefore, we suggest that the five metabolic enzymes resultant from our previous work (Carrea and Diambra, 2016) should be considered when studying T. cruzi and its implications in human health.

\section{AUTHOR CONTRIBUTIONS}

AC and LD conceived and designed the work, and analyzed and interpreted the data. AC wrote the manuscript. LD

\section{REFERENCES}

Basak, C., Pathak, S. K., Bhattacharyya, A., Pathak, S., Basu, J., and Kundu, M. (2005). The secreted peptidyl prolyl cis,trans-isomerase hp0175 of helicobacter pylori induces apoptosis of gastric epithelial cells in a tlr4-and apoptosis signal-regulating kinase 1-dependent manner. J. Immunol. 174, 5672-5680. doi: 10.4049 /jimmunol.174.9.5672

Carrea, A., and Diambra, L. (2016). Systems biology approach to model the life cycle of Trypanosoma cruzi. PLoS ONE 11:e0146947. doi:10.1371/journal.pone.0146947

Collingridge, P. W., Brown, R. W., and Ginger, M. L. (2010). Moonlighting enzymes in parasitic protozoa. Parasitology 137, 1467-1475. doi: $10.1017 /$ S0031182010000259

De Spicer, P. O., and Maloy, S. (1993). Puta protein, a membrane-associated flavin dehydrogenase, acts as a redox-dependent transcriptional regulator. Proc. Natl. Acad. Sci. U.S.A. 90, 4295-4298. doi: 10.1073/pnas.90.9.4295

De Spicer, P. O., O'Brien, K., and Maloy, S. (1991). Regulation of proline utilization in salmonella typhimurium: a membrane-associated dehydrogenase binds dna in vitro. J. Bacteriol. 173, 211-219. doi: 10.1128/jb.173.1.211-219.1991

Ferreira, É. R., Horjales, E., Bonfim-Melo, A., Cortez, C., da Silva, C. V., De Groote, M., et al. (2016). Unique behavior of trypanosoma cruzi mevalonate kinase: a conserved glycosomal enzyme involved in host cell invasion and signaling. Sci. Rep. 6:24610. doi: 10.1038/srep24610

Fujii, Y., Kimoto, H., Ishikawa, K., Watanabe, K., Yokota, Y., Nakai, N., et al. (2001). Taxon-specific $\zeta$-crystallin in japanese tree frog (hyla japonica) lens. J. Biol. Chem. 276, 28134-28139. doi: 10.1074/jbc.M102880200

Ginger, M. L. (2014). Protein moonlighting in parasitic protists. Biochem. Soc. Trans. 42, 1734-1739. doi: 10.1042/BST20140215

Gunka, K., Newman, J. A., Commichau, F. M., Herzberg, C., Rodrigues, C., Hewitt, L., et al. (2010). Functional dissection of a trigger enzyme: mutations of the bacillus subtilis glutamate dehydrogenase rocg that affect differentially its catalytic activity and regulatory properties. J. Mol. Biol. 400, 815-827. doi: 10.1016/j.jmb.2010.05.055

Hernández, S., Ferragut, G., Amela, I., Perez-Pons, J., Piñol, J., Mozo-Villarias, A., et al. (2014). Multitaskprotdb: a database of multitasking proteins. Nucleic Acids Res. 42, D517-D520. doi: 10.1093/nar/gkt1153

Huberts, D. H., and van der Klei, I. J. (2010). Moonlighting proteins: an intriguing mode of multitasking. Biochimica et Biophysica Acta 1803, 520-525. doi: $10.1016 /$ j.bbamcr.2010.01.022

Jeffery, C. J. (1999). Moonlighting proteins. Trends Biochem. Sci. 24, 8-11. doi: $10.1016 /$ S0968-0004(98)01335-8

Jeffery, C. J. (2009). Moonlighting proteins-an update. Mol. BioSyst. 5, 345-350. doi: 10.1039/b900658n

Jeffery, C. J. (2014). An introduction to protein moonlighting. Biochem. Soc. Trans. 42, 1679-1683. doi: 10.1042/BST20140226

Jeffery, C. J. (2015). Why study moonlighting proteins? Front. Genet. 6:211. doi: $10.3389 /$ fgene.2015.00211

Jin, Z.-G., Lungu, A. O., Xie, L., Wang, M., Wong, C., and Berk, B. C. (2004). Cyclophilin a is a proinflammatory cytokine that activates endothelial cells. Arterioscler. Thromb. Vasc. Biol. 24, 1186-1191. doi: 10.1161/01.ATV.0000130664.51010.28 critically revised the manuscript. AC and LD approved the final manuscript.

\section{FUNDING}

$\mathrm{AC}$ is a postdoctoral fellow of the CONICET (Argentina). LD is a research member of the CONICET (Argentina).

\section{ACKNOWLEDGMENTS}

The authors wish to thank Prof. Rolando Rivera-Pomar for his valuable suggestions during the conception of this work.

Khan, I., Chen, Y., Dong, T., Hong, X., Takeuchi, R., Mori, H., et al. (2014). Genome-scale identification and characterization of moonlighting proteins. Biol. Dir. 9, 1. doi: 10.1186/s13062-014-0030-9

Khan, I. K., and Kihara, D. (2014). Computational characterization of moonlighting proteins. Biochem. Soc. Trans. 42, 1780-1785. doi: 10.1042/BST20140214

Mani, M., Chen, C., Amblee, V., Liu, H., Mathur, T., Zwicke, G., et al. (2015). Moonprot: a database for proteins that are known to moonlight. Nucleic Acids Res. 43, D277-D282. doi: 10.1093/nar/gku954

Mantilla, B. S., Paes, L. S., Pral, E. M., Martil, D. E., Thiemann, O. H., FernándezSilva, P., et al. (2015). Role of $\delta 1$-pyrroline-5-carboxylate dehydrogenase supports mitochondrial metabolism and host-cell invasion of trypanosoma cruzi. J. Biol. Chem. 290, 7767-7790. doi: 10.1074/jbc.M114.574525

Moore, B., Zhou, L., Rolland, F., Hall, Q., Cheng, W.-H., Liu, Y.-X., et al. (2003). Role of the Arabidopsis glucose sensor hxk1 in nutrient, light, and hormonal signaling. Science 300, 332-336. doi: 10.1126/science.1080585

Moreno, F., and Herrero, P. (2002). The hexokinase 2-dependent glucose signal transduction pathway of saccharomyces cerevisiae. FEMS Microbiol. Rev. 26, 83-90. doi: 10.1111/j.1574-6976.2002.tb00600.x

Piatigorsky, J., O’Brien, W. E., Norman, B. L., Kalumuck, K., Wistow, G. J., Borras, T., et al. (1988). Gene sharing by delta-crystallin and argininosuccinate lyase. Proc. Natl. Acad. Sci. U.S.A. 85, 3479-3483. doi: 10.1073/pnas.85. 10.3479

Rao, P. V., Krishna, C. M., and Zigler, J. S. (1992). Identification and characterization of the enzymatic activity of zeta-crystallin from guinea pig lens. a novel nadph: quinone oxidoreductase. J. Biol. Chem. 267, 96-102.

Rasch, J., Ünal, C. M., and Steinert, M. (2014). Peptidylprolyl cis-trans isomerases of legionella pneumophila: virulence, moonlighting and novel therapeutic targets. Biochem. Soc. Trans. 42, 1728-1733. doi: 10.1042/BST20140202

Sukumaran, S. K., Fu, N. Y., Tin, C. B., Wan, K. F., Lee, S. S., and Yu, V. C. (2010). A soluble form of the pilus protein fima targets the VDAC-hexokinase complex at mitochondria to suppress host cell apoptosis. Mol. Cell 37, 768-783. doi: 10.1016/j.molcel.2010.02.015

Tonelli, R. R., Silber, A. M., Almeida-de Faria, M., Hirata, I. Y., Colli, W., and Alves, M. J. M. (2004). l-proline is essential for the intracellular differentiation of trypanosoma cruzi. Cell. Microbiol. 6, 733-741. doi: 10.1111/j.1462-5822.2004.00397.x

Wood, J. M. (1981). Genetics of l-proline utilization in escherichia coli. J. Bacteriol. $146,895-901$.

Conflict of Interest Statement: The authors declare that the research was conducted in the absence of any commercial or financial relationships that could be construed as a potential conflict of interest.

Copyright (C) 2017 Carrea and Diambra. This is an open-access article distributed under the terms of the Creative Commons Attribution License (CC BY). The use, distribution or reproduction in other forums is permitted, provided the original author(s) or licensor are credited and that the original publication in this journal is cited, in accordance with accepted academic practice. No use, distribution or reproduction is permitted which does not comply with these terms. 